
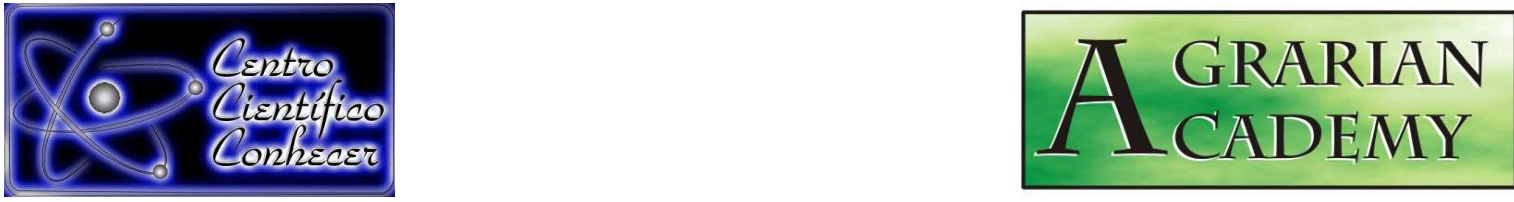

\title{
DIVERGÊNCIA GENÉTICA ENTRE PROGÊNIES DE MEIOS-IRMÃOS DE CAJUEIRO ANÃO PRECOCE UTILIZANDO CARACTERES MORFOLÓGICOS
}

José Itamar Frota Júnior ${ }^{1}$, Eveline Nogueira Lima², Maria Emília Bezerra de Araújo $^{3}$, Ingrid Bernardo de Lima ${ }^{4}$, Joilson Silva Lima ${ }^{5}$.

${ }^{1}$ Doutor em Biotecnologia/Professor assistente III, Centro Universitário Estácio/FIC,

Fortaleza, Brasil. E-mail: itamarfrota@yahoo.com.br

${ }^{2}$ Doutoranda em Agronomia/Fitotecnia, Universidade Federal do Ceará, Fortaleza, Brasil

${ }^{3}$ Mestranda em Agronomia/ Engenharia Agrícola, Universidade Federal do Ceará, Fortaleza, Brasil

${ }^{4}$ Doutoranda em Agronomia/Fitotecnia, Universidade Federal do Ceará, Fortaleza, Brasil

${ }^{5}$ Doutorando em Agronomia/Fitotecnia, Universidade Federal do Ceará, Fortaleza, Brasil

Recebido em: 05/12/2014 - Aprovado em: 14/12/2014 - Publicado em: 15/12/2014

\section{RESUMO}

O presente trabalho foi desenvolvido com o objetivo de caracterizar marcadores morfológicos de progênies de cajueiro, no intuito de selecionar progênies mais divergentes para realização de cruzamentos, visando à geração de genótipos superiores e o desenvolvimento de clones comerciais. Foram utilizadas 50 progênies de cajueiro anão precoce da coleção da Embrapa Agroindústria Tropical, instaladas no Campo Experimental de Pacajus-CE. Foram utilizadas as seguintes variáveis: altura da planta, diâmetro da copa, número de castanhas e produção. Utilizou-se a Distância Euclidiana para análise da distância genética e os métodos de Tocher e UPGMA para a análise de agrupamento. A produção foi a variável que obteve maior contribuição relativa para a divergência genética com 97,80\%. A utilização do método de otimização de Tocher, fundamentado na dissimilaridade expressa pela Distância Euclidiana, possibilitou a distribuição de 11 grupos, além da formação de 15 subgrupos. O material mais divergente foi o CNPAT 92-331 oriundo da Fazenda Capisa, Os mais similares formaram o subgrupo I; CNPAT 92-54 e CNPAT 92-58 com 95\% de similaridade.

PALAVRAS-CHAVE: Distância Euclidiana, Divergência genética, Melhoramento genético. 


\title{
GENETIC DIVERGENCE AMONG PROGENIES HALF-BROTHERS DWARF CASHEW USING MORPHOLOGICAL CHARACTERISTICS
}

\begin{abstract}
This study was conducted with the objective to characterize morphological markers of progeny cashew of Embrapa, as well as selecting the most divergent offspring to carry crossing in order to generate superior genotypes and the development of commercial clones. 50 progenies of dwarf cashew installed at the Experimental Field of Pacajús CE were used. Were used the following variables: plant height, crown diameter, number and production of cashews. Euclidean distance was used for the analysis of genetic distance. UPGMA and Tocher method were used for cluster analysis. The production was the variable with highest relative contribution to divergence with $97.80 \%$. The use of the Tocher method, based on dissimilarity expressed by Euclidean distance, enabled the distribution of eleven groups, besides the formation of 15 subgroups. The material most divergent was CNPAT 92-331 arising of Capisa Farm and the more similar was form the subgroup I; CNPAT CNPAT 92-54 and 92-58 with 95\% similarity.
\end{abstract}

KEYWORDS: Euclidian distance, Breeding, Morphological markers.

\section{INTRODUÇÃO}

O cajueiro (Anacardium occidentale L.) é uma planta tropical originária do Brasil (GIANG et al., 2013), que tem como centro de dispersão o litoral do Nordeste brasileiro. No entanto, encontra-se hoje espalhado por quase todo o território nacional, além de países da África e da Ásia. Apesar de ser encontrado praticamente em todos os estados brasileiros, adapta-se melhor às condições ecológicas do litoral do Nordeste (BRAINER et al., 2006). Segundo CARDOSO \& VIANA (2011), relatos inéditos dos primeiros colonizadores, atestando a disseminação e o uso do cajueiro, além da ocorrência de todas as espécies de Anacardium no continente americano, demonstram, de maneira inquestionável, a origem brasileira dessa frutífera.

O gênero Anacardium L. pertence à família anacardiaceae (BARROSO, 1999 citado por REIS et al., 2014) é bastante conhecido devido à amêndoa da castanha do caju (ACC) , uma deliciosa e nutritiva amêndoa produzida por plantas de cajueiro (VIEIRA et al., 2014). É considerada uma das mais importantes espécies cultivadas das regiões tropicais (AMORIM et al., 2011).

De acordo com a FAO (2013), a produção mundial de castanha de caju in natura da safra 2011 foi contabilizada em 4.201.010 toneladas. Onde Vietnam, Nigéria, Índia, Costa do Marfim, Brasil, Filipinas, Guiné-Bissau e Indonésia foram os principais produtores de castanha de caju. No Brasil em 2013 a área colhida e a produção de ACC são respectivamente de aproximadamente 708.430 ha e 259.950 toneladas, considerando a área plantada em todos os estados produtores de caju em 2012 (IBGE, 2013).

Apesar da importância econômica e social, a cadeia do caju é desarticulada. O segmento da produção caracteriza-se pela ocorrência de mais de $90 \%$ da área plantada com cajueiro comum de porte alto, baixa produtividade, idade avançada e inadequado manejo (FRANÇA et al., 2008). A baixa produtividade das lavouras é o problema mais significativo da cajucultura no Brasil, com média de $220 \mathrm{~kg}$ de castanhas in natura por 
hectare, razão pela qual são buscados cultivares mais produtivos (BARROS , 1995). No entanto, é possível se obter, em condições favoráveis, produtividades de 600 a 1.200 $\mathrm{kg}$ de castanha por hectare, desde que utilizada a tecnologia adequada, e plantas com maior potencial produtivo (OLIVEIRA, 2007).

Diversos fatores contribuem para a baixa produtividade dos atuais plantios, dentre eles a propagação realizada por sementes é a principal, já que o cajueiro é uma espécie predominantemente alógama, o que resulta na heterogeneidade de diversos caracteres da planta (CRISÓSTOMO et al.,1992; BARROS et al., 2002; PAIVA \& BARROS, 2004). Entretanto, os programas de melhoramento genético do cajueiro têm obtido excelentes resultados e, uma ferramenta de grande importância para auxiliar na superação desses problemas tem sido a seleção assistida por marcadores moleculares (SAM), que consiste na integração de informações da genética molecular com a seleção fenotípica e, que se estabelece como uma das mais potentes estratégias para o melhoramento de plantas (LANDE \& THOMPSON, 1990).

A diversidade genética entre um grupo de genitores tem sido avaliada objetivandose identificar combinações híbridas de maior heterose e maior efeito heterótico, de modo que, em suas gerações segregantes, se obtenha uma possibilidade maior de se recuperar genótipos superiores (FIGUEIRÊDO et al., 2007). Este trabalho teve como objetivo caracterizar e avaliar a diversidade genética de progênies do banco ativo de gemoplasma da Embrapa Agroindústria Tropical por meio de marcadores morfológicos.

\section{MATERIAL E MÉTODOS}

Foram utilizadas no estudo, 50 progênies de meio-irmãos de cajueiro anão precoce oriundos da coleção da Embrapa Agroindústria Tropical instalada no Campo Experimental de Pacajus - Ceará - Brasil, cujas coordenadas geográficas são 4ำ10' S e $38^{\circ} 27^{\prime} \mathrm{W}$ e a altitude de $60 \mathrm{~m}$ acima do nível do mar. O experimento foi implantado em 1993 possuindo 600 plantas, sendo 49 progênies e 1 testemunha (CP 06), oriundas dos estados do Piauí e Ceará.

O delineamento experimental original foi constituído em blocos ao acaso com 50 tratamentos, três repetições (Tabela 1), com quatro plantas/parcela, no entanto para este trabalho não foi considerado este delineamento. 
TABELA 1. Progênies instaladas no campo experimental da Embrapa em Pacajus-CE.

\begin{tabular}{|c|c|c|}
\hline $\begin{array}{c}\text { Identificação } \\
\text { (dendrograma) }\end{array}$ & $\begin{array}{c}\text { Progênie } \\
\text { tratamento }\end{array}$ & Origem \\
\hline 01 & CNPAT 92-01 & Faz. Capisa \\
\hline 02 & CNPAT 92-05 & Faz. Capisa \\
\hline 03 & CNPAT 92-10 & Faz. Capisa \\
\hline 04 & CNPAT $92-11$ & Faz. Capisa \\
\hline 05 & CNPAT 92-20 & Faz. Capisa \\
\hline 06 & CNPAT 92-26 & Faz. Capisa \\
\hline 07 & CNPAT 92-27 & Faz. Capisa \\
\hline 08 & CNPAT 92-30 & Faz. Capisa \\
\hline 09 & Progênie CP 06 & Progênie CP 06 \\
\hline 10 & CNPAT 92-40 & Faz. Capisa \\
\hline 11 & CNPAT92-45 & Faz. Capisa \\
\hline 12 & CNPAT 92-46 & Faz. Capisa \\
\hline 13 & CNPAT 92-50 & Faz. Capisa \\
\hline 14 & CNPAT 92-52 & Faz. Capisa \\
\hline 15 & CNPAT $92-54$ & Faz. Capisa \\
\hline 16 & CNPAT 92-56 & Faz. Capisa \\
\hline 17 & CNPAT 92-58 & Faz. Capisa \\
\hline 18 & CNPAT $92-62$ & Faz. Capisa \\
\hline 19 & CNPAT 92-67 & Faz. Capisa \\
\hline 20 & CNPAT 92-71 & Faz. Capisa \\
\hline 21 & CNPAT 92-73 & Faz. Capisa \\
\hline 22 & CNPAT 92-76 & Faz. Itaueira \\
\hline 23 & CNPAT 92-83 & Faz. Itaueira \\
\hline 24 & CNPAT 92-88 & Faz. Itaueira \\
\hline 25 & CNPAT 92-92 & Faz. Itaueira \\
\hline 26 & CNPAT $92-312$ & Faz. Capisa \\
\hline 27 & CNPAT $92-314$ & Faz. Capisa \\
\hline 28 & CNPAT $92-322$ & Faz. Capisa \\
\hline 29 & CNPAT 92-323 & Faz. Capisa \\
\hline 30 & CNPAT 92-327 & Faz. Capisa \\
\hline 31 & CNPAT $92-329$ & Faz. Capisa \\
\hline 32 & CNPAT $92-330$ & Faz. Capisa \\
\hline 33 & CNPAT 92-331 & Faz. Capisa \\
\hline 34 & CNPAT 92-333 & Faz. Capisa \\
\hline 35 & CNPAT $92-335$ & Faz. Capisa \\
\hline 36 & CNPAT 92-337 & Faz. Capisa \\
\hline 37 & CNPAT 92-338 & Faz. Capisa \\
\hline 38 & CNPAT 92-339 & Faz. Capisa \\
\hline 39 & CNPAT $92-342$ & Faz. Capisa \\
\hline 40 & CNPAT $92-343$ & Faz. Capisa \\
\hline 41 & Progênie CP 06 & Progênie CP 06 \\
\hline 42 & CNPAT 92-346 & Faz. Capisa \\
\hline 43 & CNPAT 92-347 & Faz. Capisa \\
\hline 44 & CNPAT 92-353 & Faz. Capisa \\
\hline 45 & CNPAT 92-354 & Faz. Capisa \\
\hline 46 & CNPAT $92-371$ & Faz. Capisa \\
\hline 47 & CNPAT 92-377 & Faz. Capisa \\
\hline 48 & CNPAT 92-378 & Faz. Capisa \\
\hline 49 & CNPAT 92-382 & Faz. Capisa \\
\hline 50 & CNPAT $92-385$ & Faz. Capisa \\
\hline
\end{tabular}


No intuito de avaliar variáveis quantitativas foram coletados junto à Embrapa Agroindústria Tropical, dados do experimento das seguintes características: média do diâmetro da copa e altura da planta (intervalo de dois anos consecutivos); média da produção por planta em gramas e número de castanhas por planta (intervalo de três anos consecutivos).

As medidas de dissimilaridade foram calculadas por meio da distância Euclidiana obtida a partir das médias das progênies conforme proposto por CRUZ \& REGAZI (1997). Conforme recomendação desses autores, em virtude das diferentes escalas de mensuração dos dados originais, esses foram padronizados antes da análise.

As análises estatísticas dos dados obtidos foram realizadas por meio do estudo da divergência genética por análise de agrupamento. A análise de agrupamento foi realizada aplicando-se a distância Euclidiana média, baseado na ligação média (UPGMA) e método de Tocher. A obtenção das médias foi realizada utilizando-se o aplicativo Microsoft Excel e os cálculos da divergência genética foram realizados por meio do aplicativo GENES (CRUZ, 2006).

Além do estudo para formação de grupos, também foram efetuadas as seguintes etapas: investigação da contribuição relativa de cada caráter para a divergência genética; estimativa da maior distância, dentre o conjunto de menores distâncias, entre cada progênie; estimativa das distâncias médias intergrupos correspondentes aos grupos formados.

Subsequentemente procedeu-se à elaboração da dispersão gráfica, utilizando os resultados da análise de conglomeração intra e intergrupos entre as progênies, os quais foram obtidos com base na estatística (D) Euclidiana. Todas as análises foram realizadas utilizando-se o aplicativo computacional GENES (CRUZ \& REGAZI, 1997).

O experimento recebeu tratos culturais como roçagem e poda drástica, esta última com o intuito de renovar a copa das árvores, assim como, eliminar possíveis galhos, ramos praguejados, ou com fonte de inóculo.

\section{RESULTADOS E DISCUSSÃO}

As distâncias $D$ mínimas e máximas entre as progênies estudadas estão apresentadas na Tabela 2. Verificam-se nas distâncias máximas que a maior parte das progênies avaliadas, apresentaram suas distâncias $D$ máximas quando combinadas com a progênie 33 (CNPAT 92-331), sendo os maiores valores de divergência genética obtidos entre as progênies 33 (CNPAT 92 - 331) e 24 (CNPAT 92 - 88) (D=9.838002), indicando que a progênie CNPAT 92 - 331 como a mais divergente entre todas

O menor valor D foi atribuído às progênies 15 (CNPAT 92 - 54) e 17 (CNPAT 92 58) $(D=0,196645)$ indicando grande similaridade entre essas duas progênies para os caracteres estudados. A maior similaridade genética pode ser atribuída a uma base genética semelhante, em virtude de ambas as progênies serem oriundas do programa de melhoramento da Embrapa Agroindústria Tropical, ambas as progênies são também oriundas do mesmo local (Fazenda Capisa). 
TABELA 2. Distâncias Euclidianas máximas e mínimas entre as 50 progênies de caju.

\begin{tabular}{|c|c|c|c|c|}
\hline \multirow{2}{*}{ Progênies } & \multicolumn{4}{|c|}{ Distância entre progênies (D) } \\
\hline & Mínimas & & Máximas & \\
\hline 1 - CNPAT 92-01 & 0,566030 & 47 & 7.831182 & 33 \\
\hline 2 - CNPAT $92-05$ & 0,405576 & 40 & 7.012415 & 33 \\
\hline 3 - CNPAT $92-10$ & 0,689864 & 20 & 8.037796 & 33 \\
\hline 4 - CNPAT $92-11$ & 0,462259 & 40 & 6.756918 & 33 \\
\hline 5 - CNPAT 92 - 20 & 0,983963 & 35 & 6.977633 & 33 \\
\hline 6 - CNPAT $92-26$ & 0,916708 & 12 & 5.809638 & 33 \\
\hline 7 - CNPAT $92-27$ & 0,437957 & 11 & 6.82554 & 33 \\
\hline 8 - CNPAT $92-30$ & 0,399293 & 21 & 8.796137 & 33 \\
\hline $9-\mathrm{CP} 06-\mathrm{T}$ & 0,807563 & 17 & 9.360662 & 33 \\
\hline 10 - CNPAT $92-40$ & 0,776043 & 16 & 8.042723 & 33 \\
\hline 11 - CNPAT $92-45$ & 0,437957 & 7 & 7.00353 & 33 \\
\hline 12 - CNPAT $92-46$ & 0,916708 & 6 & 6.009099 & 33 \\
\hline 13 - CNPAT $92-50$ & 0,380082 & 27 & 8.34521 & 33 \\
\hline 14 - CNPAT $92-52$ & 0,361166 & 44 & 8.434457 & 33 \\
\hline 15 - CNPAT $92-54$ & 0,196645 & 17 & 9,637268 & 33 \\
\hline 16 - CNPAT $92-56$ & 0,776043 & 10 & 7.489087 & 33 \\
\hline 17 - CNPAT $92-58$ & 0,196645 & 15 & 9.491659 & 33 \\
\hline 18 - CNPAT $92-62$ & 0,687846 & 42 & 8.581842 & 33 \\
\hline 19 - CNPAT $92-67$ & 0,271586 & 50 & 8.378056 & 33 \\
\hline 20 - CNPAT $92-71$ & 0,689864 & 03 & 8.391821 & 33 \\
\hline 21 - CNPAT $92-73$ & 0,289055 & 27 & 8.810114 & 33 \\
\hline 22 - CNPAT 92 - 76 & 0,407515 & 17 & 9.09952 & 33 \\
\hline 23- CNPAT 92 - 83 & 0,246280 & 18 & 9.15565 & 33 \\
\hline 24 - CNPAT $92-88$ & 0,555721 & 15 & 9.838002 & 33 \\
\hline 25 - CNPAT 92 - 92 & 0,552199 & 28 & 8.76157 & 33 \\
\hline 26 - CNPAT $92-312$ & 0,361886 & 44 & 8.055585 & 33 \\
\hline 27 - CNPAT $92-314$ & 0,289055 & 21 & 8.523275 & 33 \\
\hline 28 - CNPAT $92-322$ & 0,534020 & 14 & 8.211826 & 33 \\
\hline 29 - CNPAT $92-323$ & 0,919772 & 45 & 6.914409 & 33 \\
\hline 30 - CNPAT 92 -327 & 0,484870 & 11 & 7.328827 & 33 \\
\hline 31 - CNPAT $92-329$ & 1.076154 & 34 & 7.407616 & 33 \\
\hline 32 - CNPAT 92 - 330 & 1.188369 & 39 & 5.556375 & 24 \\
\hline 33 - CNPAT $92-331$ & 4.483079 & 32 & 9.838002 & 24 \\
\hline 34 - CNPAT 92 - 333 & 0,955505 & 37 & 7.421194 & 33 \\
\hline 35 - CNPAT 92 - 335 & 0,807175 & 26 & 7.700528 & 33 \\
\hline 36 - CNPAT $92-337$ & 0,688559 & 28 & 7.911739 & 33 \\
\hline 37 - CNPAT 92 - 338 & 0,360376 & 41 & 6.981741 & 33 \\
\hline 38 - CNPAT 92 - 339 & 0,808265 & 43 & 6.44053 & 33 \\
\hline 39 - CNPAT 92 - 342 & 1.188369 & 32 & 5.972785 & 24 \\
\hline 40 - CNPAT $92-343$ & 0,405576 & 02 & 6.915974 & 33 \\
\hline 41 - CNPAT 92 - T & 0,215490 & 45 & 7.240775 & 33 \\
\hline 42 - CNPAT $92-346$ & 0,687846 & 18 & 7.935696 & 33 \\
\hline 43 - CNPAT $92-347$ & 0,808265 & 38 & 6.144762 & 33 \\
\hline 44 - CNPÁT 92 - 353 & 0,356502 & 50 & 8.343956 & 33 \\
\hline 45 - CNPAT $92-354$ & 0,215490 & 21 & 7.177843 & 33 \\
\hline 46 - CNPAT 92 - 371 & 0,697656 & 18 & 8.290045 & 33 \\
\hline 47 - CNAPT 92 - 377 & 0,319760 & 48 & 7.841135 & 33 \\
\hline 48 - CNPAT $92-378$ & 0,319760 & 47 & 7.761972 & 33 \\
\hline 49 - CNPAT 92 - 382 & 0,932925 & 12 & 6.062398 & 33 \\
\hline 50 - CNPAT $92-385$ & 0,271586 & 19 & 8.329785 & 33 \\
\hline
\end{tabular}

AGRARIAN ACADEMY, Centro Científico Conhecer - Goiânia, v.1, n.02; p. $\quad 522014$ 
O menor valor D foi atribuído às progênies 15 (CNPAT 92 - 54) e 17 (CNPAT 92 58) $(D=0,196645)$ indicando grande similaridade entre essas duas progênies para os caracteres estudados. A maior similaridade genética pode ser atribuída a uma base genética semelhante, em virtude de ambas as progênies serem oriundas do programa de melhoramento da Embrapa Agroindústria Tropical, ambas as progênies são também oriundas do mesmo local (Fazenda Capisa).

A progênie CNPAT 92-88 (24) oriunda de Canto do Buriti (Pi) (Fazenda Itaueira) se destaca também com distância significativa entre as seguintes progênies: CNPAT 92-330 (32), CNPAT 92-331 (33) e CNPAT92-342 (39), todas oriundas da Fazenda Capisa.

Verifica-se também que a progênie CNPAT 92-331 (33) obteve a menor distância $(\mathrm{D}=4,48)$ entre a progênie CNPAT 92-330 (32), oriundas da Fazenda Capisa (Pio Ix, Pi). Analisando a progênie CNPAT 92-330 (32), observou-se que diferentemente da mais divergente, CNPAT 92-331 (33), a menor distância encontrada foi com a progênie CNPAT 92-342 (32) e a maior distância com a progênie CNPAT 92-88 (24).

Pela Distância Euclidiana média pode-se sugerir que as progênies CNPAT 92-330 (32) e CNPAT 92-88 (24), CNPAT 92-331 (33) e CNPAT 92-88 (24), CNPAT 92-88 (24) e CNPAT 92-331 (33) e CNPAT 92-342 (39) e CNPAT 92-88 (24) a priori, poderão ser utilizadas no programa de melhoramento genético do cajueiro da Embrapa Agroindústria Tropical, pelo fato das mesmas terem apresentado maior distância genética $(5,56,9,83,9,83$ e 5,97) respectivamente. A progênie CNPAT 92-331 (33) foi de fato a mais divergente entre todas as demais onde neste caso se classifica como aquela que poderá ser utilizada no programa de melhoramento genético do cajueiro entre praticamente todas as demais progênies. Examinando a Tabela 3, observa-se que a variável que mais contribuiu para a divergência genética foi a produção com $97,80 \%$.

TABELA 3 - Contribuição relativa das variáveis resposta para a divergência genética em 50 progênies de cajueiro.

\begin{tabular}{cc}
\hline Variável resposta & $\begin{array}{c}\text { Contribuição relativa das variáveis resposta } \\
\text { para a divergência genética (\%) }\end{array}$ \\
\hline Altura & 0,0003 \\
Diâmetro & 0,0005 \\
Número de castanhas & 2,1943 \\
Produção & 97,8049 \\
\hline
\end{tabular}

Avaliando genótipos obtidos de cruzamentos entre cajueiro anão precoce, CAVALCANTI et al. (2003), identificaram incrementos médios de 12\%, 19\%, 98\% e $97 \%$, para altura da planta, diâmetro da copa, número de castanhas por planta e produtividade, respectivamente. Além desses caracteres, CRISÓSTOMO et al. (2002) detectaram heterose para os relacionados ao pedúnculo, com valores e até $100 \%$ para a concentração de tanino, $52 \%$ para a acidez total, 10\% para teores de sólidos solúveis, $22 \%$ para textura do pedúnculo e $-9 \%$ para o $\mathrm{Ph}$.

Já PAIVA et al. (1998) estudado os efeitos da depressão por endogamia sobre as características vegetais e de produção, aos 12, 18 e 29 meses de idade das plantas, comparando progênies de clones de cajueiro anão precoce originárias de 
autofecundações, polinizações livres e de cruzamentos controlados, mostraram pelos resultados que houve reduções significativas de até $15,4 \%$ no caráter altura da planta, $19,5 \%$ no diâmetro da copa, $11,6 \%$ no peso da castanha, $12,4 \%, 12,4 \%$ no peso da amêndoa e de $48 \%$ na produção.

CAVALCANTI et al. (2000) avaliaram a heterose em plantas oriundas do cruzamento entre tipos comum e anão precoce, constataram efeitos de $20 \%$ para a altura da planta, $32 \%$ para diâmetro da copa, 121\% para número de castanhas por planta, $192 \%$ para produtividade, $15 \%$ para peso da castanha e $19 \%$ para peso da amêndoa.

Estudos de diversidade baseados na análise de vários caracteres morfológicos, tomados de cada indivíduo ou acesso, podem ser realizados por meio do emprego de métodos multivariados. A confiabilidade dos resultados é maior quando os dados são obtidos a partir de um delineamento experimental com repetições. Entretanto, essa estratégia é muito difícil quando se trabalha com plantas perenes arbóreas, como no caso do cajueiro, e impraticável quando se avaliam indivíduos de populações naturais (PESSONI, 2007).

SAMAL et al., (2003), avaliando 20 variedades de cajueiro através de oito componentes morfométricas relacionadas com o padrão de ramificação, florescimento, razão sexual entre flores na panícula e de produção de castanha, por um período de três anos consecutivos. Baseado nas Análises de divergência na distância de Gower, e de agrupamento, por UPGMA, evidenciaram a formação de quatro grupos distintos com nível de similaridade igual ou superior a $70 \%$. Entretanto, o maior grupo foi formado por 12 genótipos, enquanto dois grupos foram formados cada um por um genótipo apenas.

Observou-se a formação de 11 grupos e 15 subgrupos (Tabela 4). Destaque para o grupo XI com apenas uma progênie (CNPAT 92-331). As 50 progênies avaliadas foram separadas em onze grupos, quando se fez um corte vertical a uma distância de ligação em torno de $18 \%$ no agrupamento hierárquico das progênies com base nas variáveis respostas avaliadas (Figura 1). Esse ponto de corte permite visualizar os onze grupos formados onde o último ficou isolado apenas com a progênie CNPAT 92-331 (33).

Pelo fato da progênie CNPAT 92-331 (33) ter constituído um grupo isolado das demais, conclui-se que a mesma seja a mais divergente entre todas as outras, onde também pode-se enfatizar as progênies CNPAT 92-330 (32) e CNPAT 92-342 (39) como as mais divergentes entre as demais. Observa-se também que as progênies CNPAT 92-76 (22), CNPAT 92-88 (24) e CNPAT 92-83 (23), todas oriundas da Fazenda Itaueira, ficaram locadas no subgrupo I do grupo I, no entanto, a progênie CNPAT 92-92 (25), também oriunda do mesmo local, ficou no subgrupo 2 do grupo 3.

Segundo RAHMAN et al., (2002), a identificação de genótipos superiores com base na divergência genética é a estratégia mais adequada para iniciar um programa de melhoramento. Sendo importante ressaltar que é mais efetivo realizar cruzamentos entre genótipos altamente divergentes, e que também apresentem bom potencial produtivo. 
TABELA 4- Subgrupos formados pelas 50 progênies de caju baseado na dissimilaridade expressa pela distância Euclidiana.

\begin{tabular}{|c|c|c|}
\hline Grupo & Subgrupo & Progênies \\
\hline \multirow[t]{2}{*}{ I } & Subgrupo I & $\begin{array}{l}\text { CNPAT } 92 \text {-54, CNPAT 92-58, CNPAT 92-76, CNPAT } \\
\text { 92-88, CNPAT 92-83. }\end{array}$ \\
\hline & Subgrupo II & Progênie CP 06. \\
\hline \multirow{2}{*}{ II } & Subgrupo I & CNPAT 92-62, CNPAT 92-346. \\
\hline & Subgrupo II & CNPAT 92-371. \\
\hline \multirow[t]{2}{*}{ III } & Subgrupo I & $\begin{array}{l}\text { CNPAT 92-377, } \\
\text { CNPAT 92-337. }\end{array}$ \\
\hline & Subgrupo II & $\begin{array}{l}\text { CNPAT 92-92, CNPAT 92-322, CNPAT 92-73, CNPAT } \\
\text { 92-314, CNPAT 92-30, CNPAT 92-50, CNPAT 92-312, } \\
\text { CNPAT 92-67, CNPAT 92-385, CNPAT 92-353, } \\
\text { CNPAT 92-52. }\end{array}$ \\
\hline IV & Subgrupo I & CNPAT 92-26, CNPAT 92-46. \\
\hline \multirow[t]{2}{*}{$\mathrm{V}$} & Subgrupo I & $\begin{array}{l}\text { CNPAT 92-05, CNPAT 92-343, CNPAT 92-11, CNPAT } \\
\text { 92-20. CNPAT 92-335. }\end{array}$ \\
\hline & Subgrupo II & $\begin{array}{l}\text { CNPAT 92-323, CNPAT 92-382, Progênie CP 06, } \\
\text { CNPAT 92-354, CNPAT 92-338, CNPAT 92-27, } \\
\text { CNPAT 92-45, CNPAT 92-327. }\end{array}$ \\
\hline $\mathrm{VI}$ & Subgrupo I & CNPAT 92-10, CNPAT 92-71. \\
\hline $\mathrm{VII}$ & Subgrupo I & CNPAT 92-339, CNPAT 92-347. \\
\hline VIII & Subgrupo I & CNPAT 92-329, CNPAT 92-333. \\
\hline IX & Subgrupo I & CNPAT 92-40, CNPAT 92-56. \\
\hline $\mathrm{X}$ & Subgrupo I & CNPAT 92-330, CNPAT 92-342. \\
\hline $\mathrm{XI}$ & Subgrupo I & CNPAT 92-331. \\
\hline
\end{tabular}




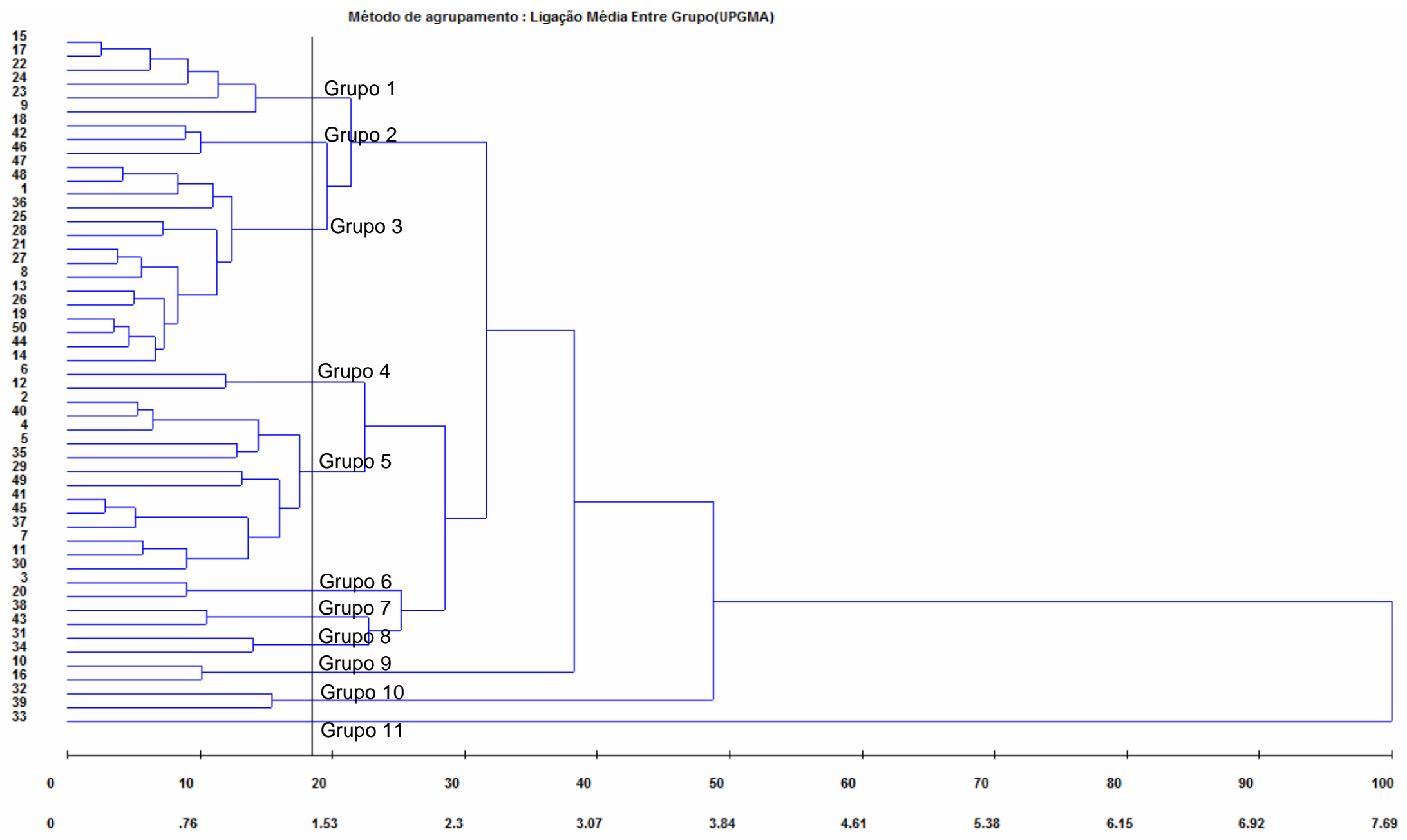

FIGURA 1. Dendograma representativo da dissimilaridade genética entre 50 progênies de cajueiro anão precoce pelo método da ligação média entre grupo (UPGMA), utilizando-se a distância Euclidiana (D) como medida de dissimilaridade. 
As progênies mais divergentes foram CNPAT 92-331 (33), CNPAT 92-342 (39) e CNPAT 92-330 (32). ARCHAK et al. (2003) comparando a eficiência e utilidade em três tipos de marcadores moleculares (RAPD, AFLP, ISSR) e de descritores morfológicos na medida de variação e de discriminação genotípica de germoplasma de caju, não foi observada a ocorrência de correlação entre o conjunto de 27 descritores morfométricas utilizados e os marcadores moleculares.

De acordo com FRANCO et al. (2001), quando se dispõe de dados fenotípicos morfológicos e de marcadores moleculares para um conjunto de genótipos, os estudos de diversidade e de classificação hierárquica são realizados de forma independente, uma análise é baseada nos dados morfológicos, através do cálculo de uma distância métrica padrão (tal como o quadrado da Distância Euclidiana) e da aplicação de uma estratégia de agrupamento como UPGMA ou Ward. Outra classificação é obtida baseada nos atributos moleculares, através da determinação da similaridade ou dissimilaridade genética entre os indivíduos, também seguido da aplicação de uma estratégia de agrupamento dos genótipos.

\section{CONCLUSÃO}

Há variabilidade genética na população em estudo que pode ser explorada no programa de melhoramento genético através da seleção de genitores para formar combinações híbridas desejáveis para a obtenção de genótipos superiores.

As progênies mais divergentes foram: CNPAT 92-331 (33), CNPAT 92-342 (39) e CNPAT 92-330 (32) e as mais similares foram CNPAT 92-54 (15) e CNPAT 92-58 (17).

Foram utilizados dados de altura da planta, diâmetro da copa, número de castanhas e produção como características morfológicas. É necessário reunir maior número de características para que haja uma maior proximidade dos valores dos resultados das análises molecular e quantitativa.

\section{REFERÊNCIAS}

AMORIM, A. V.; GOMES-FILHO, E.; BEZERRA, M. A.; PRISCO, J. T.; LACERDA, C. F. Produção e fisiologia de plantas de cajueiro anão precoce sob condições de sequeiro e irrigado. Revista Brasileira de Engenharia Agrícola e Ambiental, v.15, n.10, p.1014-1020, 2011.

ARCHAK, S; GAIWARD. A.B; GUATAM, D.; RAO, E.V.V.B.; SWAMY, K. R. M. Comparative assesment of DNA fingerprint techinques (RAPD, ISSR and AFLP) for genetic analysis of cashew (Anacardium occidentale L.) acessions of Índia. Genome, v. 46.p 363 - 369. 2003.

BARROS, L.M.; PAIVA, J.R.; CAVALCANTI, J.J.V.; ARAÚJO, J.P.P. Cajueiro. In: BRUCKNER, C.H. (Ed.). Melhoramento de fruteiras tropicais. Viçosa: UFV, p. 159-176.2002.

BARROS, L. de M. Botânica, origem e distribuição geográfica: IN: ARAÚJO, J.P.P.; SILVA, V.V (org). Cajucultura: modernas técnicas de produção. Fortaleza: EMBRAPA-CNPAT, p. 55-71.1995.

BRAINER, M. S. de C. P; E. F. R. Proposta de zoneamento para a cajucultura. Série documentos do ETENE, n.10, Fortaleza: Banco do Nordeste do Brasil, 2006. 
CARDOSO, J. E.; VIANA, F. M. P. Impacto potencial das mudanças climáticas sobre as doenças do cajueiro no Brasil. In: GHINI, R.; HAMADA, E.; BETTIOL, W. (Ed.). Impactos das mudanças climáticas sobre doenças de importantes culturas do Brasil. Jaguariúna: Embrapa Meio Ambiente, p. 161-176.2011.

CAVALCANTI, J. J. V.; PINTO, C. A. B. P.; CRISÓSTOMO, J. RFERREIRA, D. F. Análise dialélica para avaliação de híbridos interpopulacionais de cajueiro. Pesquisa Agropecuária Brasileira, v.35, n.8, p.1567-1575. 2000.

CAVALCANTI, J. J. V.; CRISOSTOMO, J. R.; BARROS, L. M.; PAIVA, J. R. Heterose em cajueiro anão precoce. Ciência e Agrotecnologia, v.27, n.3, p.565570. 2003.

CRISÓSTOMO, J.R.; CAVALCANTI, J.J.V.; BARROS, L.M.; ALVES, R.E.; FREITAS, J.G.; OLIVEIRA, J.N. Melhoramento do cajueiro-anão-precoce: avaliação da qualidade do pedúnculo e a heterose dos seus híbridos. Revista Brasileira de Fruticultura, Jaboticabal, v. 24, n. 2, p. 477-480, 2002.

CRISÓSTOMO, J.R.; GADELHA, J.W.R.; ARAÚJO, J.P.P. de; BARROS, L.de M. Consequências do plantio de sementes colhidas de plantas enxertadas ou de plantas de pé franco de cajueiro. Caju Informativo, Fortaleza, v.5, n.3. 1992.

CRUZ, C. D.; Programa Genes - Análise multivariada e simulação. 1. ed. Viçosa, MG: Editora UFV, 2006. v. 1.175 p.

CRUZ, C.D; REGAZI, A. J. Modelos biométricos aplicados ao melhoramento genético: Viçosa: UFV,1997. 390p.

FAO. Organização das Nações Unidas para Alimentação e Agricultura <https://www.fao.org.br>. Acesso em 24 de novembro de 2014.

FIGUEIREDO, E.V.; ARAGÃO, W.M.; LEAL, M. de L. da S. Divergência genética entre cultivares de coqueiro anão por meio de marcadores morfológicos: Revista Brasileira de Biociências, v.5, supl. 1, p. 804-806, jul. 2007.

FRANÇA, F. M. C.; BEZERRA, F. F.; MIRANDA, E.Q de.; SOUSA NETO, J. M de. Agronegócio do caju no Ceará: cenário atual e propostas inovadoras. Fortaleza: FIEC-INSTITUTO DE DESENVOLVIMENTO INDUSTRIAL DO CEARÁ. 114p. 2008.

FRANCO, J.; CROSS A, J.; RIBANT, J. M.; BETRA, J.; WARBURTON, M. L.; KHAIRALLAH, M. Amethod for combining molecular markers and phenotypic attributes for classifying plant genotypes. Thear. Appl. Genet. V.103, p. 944-952. 2001.

GIANG, N. T. T.; KIEU, N. T.; NAM, T. N.;DAO,D. T. A.; MINH,N. P. Cashew Apple Juice Anacardium Occidentale L.Probiotic Fermented from Lactobacillus acidophilus. European Journal of Sustainable Development, v. 2, n. 3, p. 99-108, 2013. 
IBGE. Instituto Brasileiro de Geografia e Estatística. Levantamento sistemático da produção agrícola. $<$ http://www.sidra.ibge.gov.br/tabela/protabl.asp?c=1613\&z=t\&o=11\&i=P>. Acesso em 24 de novembro de 2014.

LANDE, R.; THOMPSON, R. Efficiency of marker-assisted selection in the improvement of quantitative traits .Genetics, v. 124, p.743-756, 1990.

OLIVEIRA, F. N. S. Sistema de produção para manejo do cajueiro comum e recuperação de pomares improdutivos. Fortaleza: Embrapa Agroindústria Tropical, 2007. 36 p. (Sistemas de Produção, 2).

PAIVA, J. R; BARROS, L. M. Clones de cajueiro: obtenção, características e perspectivas. Fortaleza: Embrapa Agroindústria Tropical, 2004. 26 p. (Documentos, 82).

PAIVA, J. R.; BARROS, L. M.; CRISÓSTOMO, J. R.; ARAÚJO, J. P. P.; ROSSETI, A. G.; CAVALCANTI, J. J. V.; FELIPE, E. M. Depressão por endogamia em progênies de cajueiro anão precoce (Anacardium occidentale L.) var.nanum. Pesquisa Agropecuária Brasileira, v.33, n.4, p.425-431. 1998.

PESSONI, L.A. Estratégias de avaliação da diversidade em germoplasma de caju (Anacardium spp L.). 2007. 159p. Tese (Doutorado em genética e melhoramento).Universidade Federal de Viçosa, Viçosa, MG, 2007.

RAHMAN, M.; HUSSAIN, D.; ZAFAR, Y. Estimation of Genetic Divergence among Elite Cotton Cultivars-Genotypes by DNA Fingerprinting Technology.Crop Science.v.42. p.2137-2144, 2002. RAO, R. C. Advanced statistical methods in biometric research. New York: J. Wiley.

REIS, A. L. L. E.; SILVA, D. S.; SILVA, K. L.; CHAGAS D. B. Caracterização anatômica e histoquímica de raízes e folhas de plântulas de Anacardium occidentale L. (Anacardiaceae). Revista Árvore, v.38, n.2, p.209-219, 2014.

SAMAL, S.; ROUT, G.R.; LENKA, P.C. Analiysis of genetic relationships btween populations of cashew (Anacardium occidentale L.) by using morphological characterization and RAPD markers. Plant Soil Environ, v.49, n.4, p.176-182, 2003.

VIEIRA, M.; MAYO, S. J.; ANDRADE, I. M. Geometrics morphometrics of leaves of Anacardium microcarpum Ducke and $A$. occidentale $\mathrm{L}$. (Anacardiaceae) from the coastal region of Piauí, Brazil.Brazillian Journal of Botany.V. 37, 2014. 